\title{
The impact of different suturing techniques for abdominal fascia closure on the Interleukin-6 expressions in Rattus norvegicus
}

\author{
Heryu Prima ${ }^{1}$, Imam Sofii ${ }^{*}$, Aditya Rifqi Fauzi ${ }^{2}$, Ishandono Dachlan ${ }^{3}$ and Gunadi ${ }^{2}$
}

\begin{abstract}
Objective: Incisional hernia is a frequent complication of midline laparotomy. The suturing technique is an important determinant of the risk of developing an incisional hernia. Moreover, IL-6 has crucial roles in the wound-healing process. We aimed to compare the large stitch vs. small stitch technique for abdominal fascial closure on IL-6 expressions in rats.

Results: Twenty rats were used. The small stitch group received small tissue bites of $5 \mathrm{~mm}$ and the large stitch group received large bites of $10 \mathrm{~mm}$. The incisions of fascia were closed by running sutures. Animals were euthanized on days 4 and 7. Histological sections of the tissue-embedded sutures were analyzed for IL-6 expressions. Two-way ANOVA showed that rats in the small stitch group had similar IL-6 expressions on days 4 and 7 to those in the large stitch group $(p=0.36)$. In conclusion, the IL-6 expressions are similar between the small and the large stitch groups, implying that different suturing techniques might not have an impact on the incisional hernia occurrence.
\end{abstract}

Keywords: Abdominal fascial closure, Interleukin-6 expression, Incisional hernia, Large stitch, Small stitch

\section{Introduction}

Incisional hernia is a frequent complication of postabdominal wall incisions and causes reoperation. In various meta-analysis and meta-regression studies, the mean incidence rate of incisional hernia at 23.8 months postabdominal incision was $12.8 \%$ [1]. The occurrence of an incisional hernia has an important impact on the quality of life and body image of the patient [2]. The estimated cost of incisional hernia management reaches billions of US dollars annually [3]. Therefore, to reduce the incidence rate of incisional hernia requires optimal closure of the abdominal wall incision in order to save both cost and use of health facilities and reduce postoperative disability [1].

\footnotetext{
*Correspondence: imam.sofi@ugm.ac.id

1 Digestive Surgery Division, Department of Surgery, Faculty of Medicine, Public Health and Nursing, Universitas Gadjah Mada/Dr. Sardjito Hospital, Yogyakarta 55281, Indonesia

Full list of author information is available at the end of the article
}

The median incision is the most commonly selected incision for open abdominal surgery [4]. A number of experimental and clinical studies have shown that the quality of stitching techniques is essential for the prevention of wound complications in the median incision [5]. Incisional hernia is the late complication of fascial disruption [6]. Fascia can more efficiently pick up and activate cellular elements that are important for the proliferative phase of the abdominal incision wound healing process. The proliferation phase of wound healing begins to dominate on the fourth day after the abdominal incision and fibroblasts are the most important cellular components during this phase [7]. Observation of fibroblast cellularity and collagen staining in rats showed increased levels on the seventh day after fascial incision [8]. Fibroblasts secrete pro-inflammatory cytokines, Interleukin-6 (IL-6), in response to strain [9]. IL-6 has a direct role in the proliferation and remodeling phase of wound healing by promoting collagen and angiogenesis deposition [10].

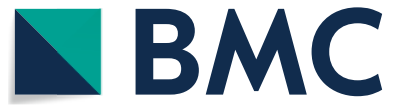

(c) The Author(s) 2020. This article is licensed under a Creative Commons Attribution 4.0 International License, which permits use, sharing, adaptation, distribution and reproduction in any medium or format, as long as you give appropriate credit to the original author(s) and the source, provide a link to the Creative Commons licence, and indicate if changes were made. The images or other third party material in this article are included in the article's Creative Commons licence, unless indicated otherwise in a credit line to the material. If material is not included in the article's Creative Commons licence and your intended use is not permitted by statutory regulation or exceeds the permitted use, you will need to obtain permission directly from the copyright holder. To view a copy of this licence, visit http://creativeco mmons.org/licenses/by/4.0/. The Creative Commons Public Domain Dedication waiver (http://creativecommons.org/publicdomain/ zero/1.0/) applies to the data made available in this article, unless otherwise stated in a credit line to the data. 
Many studies have shown a beneficial effect of the small stitch technique compared with large stitch in the prevention of incisional hernia. However, the studies did not focus on the effect of suturing techniques on IL-6 expression in the prevention of incisional hernia, so accordingly, this study aimed to compare the effects of the large stitch with the small stitch technique for abdominal fascial closure on IL-6 expressions in rats.

\section{Main text}

\section{Material and methods}

\section{Animal subjects}

An experimental study was conducted on Wistar rats (Rattus norvegicus). Twenty 170-200 g rats were selected for this study, which were adapted for a week prior to the research. Our study was in line with the guidelines of experimental animals: 3R (replacement, reduction, and refinement) and $5 \mathrm{~F}$ (freedom of hunger and thirst, freedom from discomfort, freedom of pain, injury, or disease, freedom to fear and distress, and freedom to express natural behaviour). Therefore, we determined our subjects to be 20 rats. Subjects were divided into 4 groups, consisting of four interventional groups (each consisting of 5 rats): large stitch group and euthanized on day 4 (group 1), small stitch group and euthanized on day 4 (group 2), large stitch group and euthanized on day 7 (group 3), and small stitch group and euthanized on day 4 (group 4). All rats were euthanized by decapitation. All procedures were done under sedation using ketamine (Ikapharmindo, Jakarta, Indonesia) intramuscular injection
$60 \mathrm{mg} / \mathrm{kg}$ after aseptic-antiseptic action with 1\% povidone iodine. The anesthesia was maintained by additional doses as necessary. The animals were kept supine during the experiments. Incision in the abdominal skin of mice involved a length of $6 \mathrm{~cm}$, then a $6-\mathrm{cm}$ incision in the alba line. All stitches were placed at $5 \mathrm{~mm}$ from the edge of the wound for the small stitch group and at $10 \mathrm{~mm}$ from the edge of the wound to the large stitch group. Suture technique used continuous suture and suture material was polyvinylidene fluoride monofilament. Examination of IL-6 expression of paraffin blocks used immunohistochemical assay. Counting the number of IL- 6 expressions used a counter in the Adobe Reader application. The expressions of IL- 6 appeared as dark brown cells.

\section{Statistical analysis}

Data were subjected to statistical analysis using SPSS ver. 24 (IBM Corp., New York). Normality test was done and hypothetical tests comparing each interventional group preceded 2-way ANOVA. Significance was met if $p<0.05$. The Medical and Health Research Ethics Committee of the Faculty of Medicine, Universitas Gadjah Mada approved the study (KE/FK/0151/EC/2018).

\section{Results}

After immunohistochemical staining on tissue samples of each group, the expressions of IL-6 appeared as dark brown cells (Fig. 1).
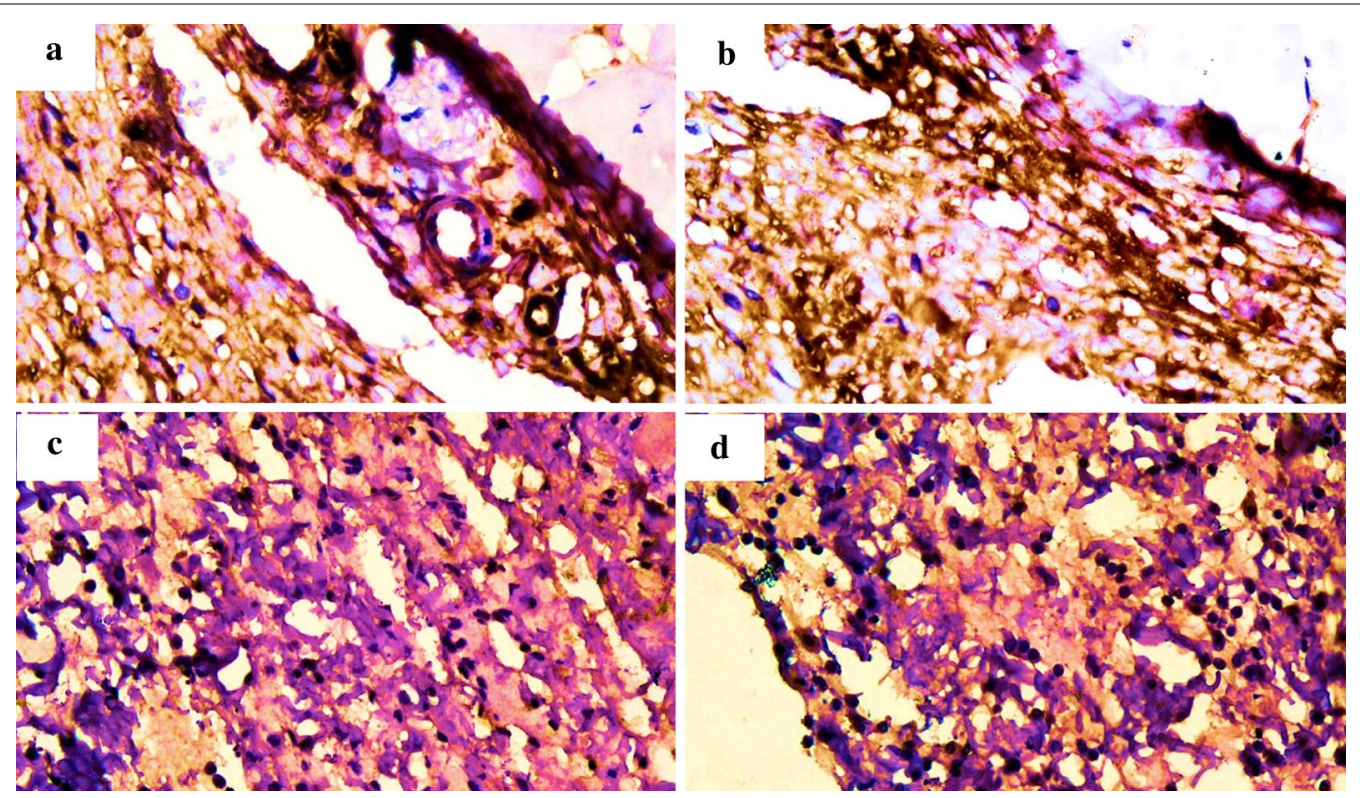

Fig. 1 IL-6 expressions in the small stitch group on: a day 4 and $\mathbf{b}$ day 7, and the large stitch group on: $\mathbf{c}$ day 4 and $\mathbf{d}$ day 7. The IL-6 expressions were similar among groups and days $(p>0.05)$ 
Table 1 Comparison of IL- 6 expressions between small and large stitch groups on days $\mathbf{4}$ and 7

\begin{tabular}{llll}
\hline & \multicolumn{2}{l}{ IL-6 expressions } & p-value \\
\cline { 2 - 3 } & Small stitch (mean \pm SD) & Large stitch (mean \pm SD) & \\
\hline Day 4 & $38.4 \pm 25.91$ & $37.13 \pm 22.75$ & $0.36^{*}$ \\
Day 7 & $69.67 \pm 43.97$ & $58.33 \pm 35.02$ & \\
\hline
\end{tabular}

IL-6 Interleukin-6, SD standard deviation; $p$-value was calculated using 2-way ANOVA

Rats in the small stitch group had similar IL-6 expressions on days 4 and 7 to those in the large stitch group $(p=0.36)$ (Table 1$)$.

\section{Discussion}

Here, we show that the effect of small and large stitch techniques is similar in the healing of abdominal fascial lesions as evidenced by similar IL-6 expression levels. IL-6 has an important role in the wound healing process by regulating the infiltration of leukocytes, angiogenesis, and collagen deposition. IL- 6 has a direct role in the proliferation and remodeling of wound healing by promoting collagen and angiogenesis deposition [10].

Millbourn et al. [11] conducted a randomized trial study and concluded that short stitch was associated with low incidence of wound infection and incisional hernias. Multivariate analysis showed that the risk of infection was doubled and the incisional hernia risk was fourfold higher in the long stitch group. The small amount of IL-6 in the long stitch group on day 4 after incision may cause fascial wound healing disorders. Fascial wound healing disorders can be caused by failure in the acute phase of inflammation. IL-6 deficiency causes immune deficiency against infections and acute phase inflammatory disorders after tissue damage and infection [12].

Fortenyl et al. [13] compared the results of abdominal wall closure based on long stitch $(10 \mathrm{~mm})$ and short stitch (interval $5 \mathrm{~mm}$ ) intervals using the same suture material which was extra-long term absorbable monofilament and concluded that small stitch interval with monofilament elastic suture is absorbed better than a large stitch interval in preventing the incisional hernia which is seen with ultrasound in 1 year after the median laparotomy. Experimental research conducted by Lin et al. [10] explains that in rats with IL- 6 deficiency there is a decrease in the number of angiogenic and fibrogenic growth factors so that angiogenesis and collagen deposition are delayed. The study by Lee et al. [14] explains IL-6-deficient mice showed an early phase delay in wound healing, as well as in hyperglycemic mice. IL-6 was significantly higher (sixfold) in hyperglycemic animals at days 1,7 , and 10 [14]. Our study shows an almost significant change in
IL-6 expression in the small stitch group between days 4 and 7. Collectively, angiogenesis and precipitation of collagen are indispensable for wound healing. It has been established that IL- 6 deficiency causes angiogenesis and delayed collagen deposition [10].

\section{Conclusions}

The expressions of IL-6 are similar between the small and the large stitch groups, implying that different suturing techniques might not have an impact on the incisional hernia occurrence.

\section{Limitations}

Our study used a relatively small number of rats and only 1-week observation.

\section{Abbreviations \\ IL-6: Interleukin-6; SD: Standard deviation.}

\section{Acknowledgements}

We are thankful to all the staff members who helped with this study. Some results for the manuscript are from Heryu Prima's thesis.

\section{Authors' contributions}

HP, IS and ID conceived the study. HP, IS and G collected and analyzed the data. HP and ARF drafted the manuscript, and IS, ID, and G critically revised the manuscript for important intellectual content. HP, IS and ID facilitated all project-related tasks. All authors have agreed to be accountable for all aspects of the work in ensuring that questions related to the accuracy or integrity of any part of the work are appropriately investigated and resolved. All authors read and approved the final manuscript.

Funding

This study had no funding source.

\section{Availability of data and materials}

All data generated or analyzed during this study are included in the submission. The raw data are available from the corresponding author on reasonable request.

\section{Ethics approval and consent to participate}

The Medical and Health Research Ethics Committee of the Faculty of Medicine, Public Health and Nursing, Universitas Gadjah Mada/Dr. Sardjito Hospital gave approval for this study (KE/FK/0151/EC/2018).

\section{Consent for publication \\ Not applicable.}

\section{Competing interests}

The authors declared no potential conflicts of interest with respect to the research, authorship, and/or publication of this article.

\section{Author details}

1 Digestive Surgery Division, Department of Surgery, Faculty of Medicine, Public Health and Nursing, Universitas Gadjah Mada/Dr. Sardjito Hospital, Yogyakarta 55281, Indonesia. ${ }^{2}$ Pediatric Surgery Division, Department of Surgery, Faculty of Medicine, Public Health and Nursing, Universitas Gadjah Mada/Dr. Sardjito Hospital, Yogyakarta 55281, Indonesia. ${ }^{3}$ Division of Plastic Reconstructive and Aesthetic Surgery, Department of Surgery, Dr. Sardjito Hospital, Faculty of Medicine, Public Health and Nursing, Universitas Gadjah Mada, Yogyakarta, Indonesia. 
Received: 5 September 2020 Accepted: 21 October 2020

Published online: 30 October 2020

\section{References}

1. Muysoms FE, et al. European Hernia Society guidelines on the closure of abdominal wall incisions. Hernia J Hernias Abdominal Wall Surg. 2015;19(1):1-24. https://doi.org/10.1007/s10029-014-1342-5.

2. van Ramshorst Gabrielle H, Eker Hasan H, Hop Wim CJ, Jeekel Johannes LJF. Impact of incisional hernia on health-related quality of life and body image: a prospective cohort study. AJS. 2012;204(2):144-50. https://doi. org/10.1016/j.amjsurg.2012.01.012

3. Lau FH, Pomahac B. Wound healing in acutely injured fascia. Wound Rep Reg. 2014;22:14-7. https://doi.org/10.1111/wrr.12165.

4. Rahbari NN, et al. Current practice of abdominal wall closure in elective surgery? Is there any consensus? BMC Surg. 2009;9(1):1-8. https://doi. org/10.1186/1471-2482-9-8

5. Israelsson LA, Millbourn D. Prevention of incisional hernias. How to close a midline incision. SurgClin N Am. 2013. https://doi.org/10.1016/j. suc.2013.06.009.

6. Mizell JS. Complications of abdominal surgical incisions. In: UpToDate Rosen M, Chen W, editors. UpToDate: Waltham, MA; 2020.

7. Xing $\mathrm{L}$, et al. Early laparotomy wound failure as the mechanism for incisional hernia formation. J Surg Res. 2013;182(1):1-8. https://doi. org/10.1016/j.jss.2012.09.009.

8. Franz MG, et al. Fascial incisions heal faster than skin: a new model of abdominal wall repair. Surgery. 2001;129(2):203-8. https://doi. org/10.1067/msy.2001.110220.
9. Liptan GL. Fascia: a missing link in our understanding of the pathology of fibromyalgia. J Bodywork Movement Ther. 2010;14(1):3-12. https://doi. org/10.1016/j.jbmt.2009.08.003.

10. Lin Z-Q. Essential involvement of IL- 6 in the skin wound-healing process as evidenced by delayed wound healing in IL-6-deficient mice. J LeukocBiol. 2003;73(6):713-21. https://doi.org/10.1189/jlb.0802397.

11. Millbourn D. Effect of stitch length on wound complications after closure of midline incisions: a randomized controlled trial. Arch Surg. 2009:144(11):1056. https://doi.org/10.1001/archsurg.2009.189.

12. Kopf $M$, et al. Impaired immune and acute-phase responses in Interleukin-6-deficient mice. Nature. 1994;368(6469):339-42. https://doi. org/10.1038/368339a0.

13. Dart AJ, Dart CM. Suture material: conventional and stimuli responsive. Comprehensive Biomater. 2011. https://doi.org/10.1016/B978-0-08-05529 4-1.00245-2.

14. Lee EG, Luckett-Chastain LR, Calhoun KN, Frempah B, Bastian A, Gallucci RM. Interleukin 6 function in the skin and isolated keratinocytes is modulated by hyperglycemia. J Immunol Res. 2019;2019:5087847. https://doi. org/10.1155/2019/5087847

\section{Publisher's Note}

Springer Nature remains neutral with regard to jurisdictional claims in published maps and institutional affiliations.
Ready to submit your research? Choose BMC and benefit from:

- fast, convenient online submission

- thorough peer review by experienced researchers in your field

- rapid publication on acceptance

- support for research data, including large and complex data types

- gold Open Access which fosters wider collaboration and increased citations

- maximum visibility for your research: over $100 \mathrm{M}$ website views per year

At BMC, research is always in progress.

Learn more biomedcentral.com/submissions 